\title{
The Effect of Occupational Health and Safety Management on Performance in the Banking Sector, Ghana
}

\author{
Gilbert Joshua Atteh Sewu ${ }^{1}$, Emmanuel Gyabeng ${ }^{1}$, Adelaide Angela Dadzie ${ }^{2} \&$ Nana Kwame Nkrumah ${ }^{1}$ \\ ${ }^{1}$ Department of Management Science and Engineering, School of Management, Jiangsu University, China \\ ${ }^{2}$ Department of Environmental Science and Safety, School of Environmental Science and Engineering, Jiangsu \\ University, China
}

Correspondence: Gilbert Joshua Atteh Sewu, Department of Management Science and Engineering, School of Management, Jiangsu University, PR, China. E-mail: atteco8@yahoo.com

Received: March 24, 2019

doi:10.5539/ijbm.v14n10p172
Accepted: August 5, 2019

Online Published: September 7, 2019

\begin{abstract}
A survey was conducted to investigate the impact of occupational health and safety measures (OHSMs) on the performance of Banks in Ghana. Questionnaires were administered to employees of various Banks in the country. Using a Likert scale, respondents were asked to assess the impact of OHSMs on the performance of their Banks. The reliability of the survey data collected was tested using Cronbach's alpha. Subsequently, Pearson correlation and simple regression were used to understand the statistical relationships between variables in terms of the magnitude and the direction (positive or negative) and to determine the degree of variance among dependent and independent variables. Findings suggest that there was a slightly moderate positive correlation between OHSMs and performance of Banks. Although employees generally agreed that OHSMs were in practice, the measures should be improved and government should reinforce policies for the implementation of OHSMs and ensure compliance by the Banks.
\end{abstract}

Keywords: occupational health and safety, OHSMs, OHS impact, performance of Banks, Ghana

\section{Introduction}

Over the past years, Ghana has been potentially recognized as West African powerhouse due to the rich history and one of the steady GDP's per capita in the West African sub-region. The banking sectors currently assist the government and its agencies to ease the challenges of the nation's public deficit by assuring a strong and effective steady flow of government revenue and Ghana's bank are helping to get the economy back on track. It is no doubt that the Ghanaian banking sector contributes greatly to the nation's Gross Domestic Product (GDP) due to its financial intermediation role and as well the social role it plays through employment.

Despite the contribution of the banking sector to economic growth in Ghana, the sector faces internal challenges such as work related accidents. Ghana as a developing country is making a conscious effort to prevent or curb work-related accidents and injuries in order to increase productivity and improve performance. In this situation, the causes of accidents in the banking sector according to research studies are characterized by some of the following factors: Poor OHS characters and behaviours of the organization, lack of Personal Protective Equipment (PPE), workers disregard for OHS policies and regulations, mistakes by workers based on the lack of understanding of the OHS manuals, lack of trainings or education on safety programs, instructions, lack of risk management assessment, lack of risk monitoring devices and detectors etc. In other words, the causes of accidents in the banking sector are characterized by lack of managerial control and also negligence by employees to adhere to safety precautions. Ghana as a developing country recently, has a rapid growth in the banking sector but the banking sectors do not practice OHS thoroughly because a careful attention is not given to OHSM systems. Accidents and injuries can be alleviated or lessened by the banking sectors by implementing OHS policies, rules and regulations, safety standards and also enacting it by management in order to reduce accidents and risks which will minimize a lot of damages to the organizations or businesses financial strength and stability. In this case, promoting or policy implementations will create jobs and also promote and encourage entrepreneurship.

Employees are not only obliged to the organization; they expect management to address their health and safety 
needs first by implementing good and sound policies (Amponsah-Tawiah and Mensah 2016). The banking sectors play an active and enormous role in boosting the economy in Ghana. The banking sectors in this situation must play a vital role in OHS for sustainable development and long-term survival, with ILO statistics reporting that approximately 317 million occupational accidents occur worldwide each year and about 6,300 people die of it (Gopang, Nebhwani et al. 2017). The World Health Organization (2016) reported that the rate of input by the global workforce contributes to about USD 21.6 trillion per year of the global gross domestic product (GDP). A report from the International Labour Organization, (2015) showed that millions of workers worldwide are exposed to risk of various types of work-related hazards. The Mining, Construction, Energy, Telecommunication, Food Processing, Agro, Transport, Oil and Gas among many other industries including the service sector has contributed massively to the country's employment as the minimum standards set by ILO has not been met by most organizations (ILO,2006). The situation of OHSMs in organizations changes from time to time and varies from country to country, and injuries and fatalities are widespread in most developing countries.

From an economic point of view, the additional incurred cost associated with occupational accidents, injuries and illnesses are certainly not desired by firms. There is loss of wages, price to pay for medical treatment, pain and reduced quality of life for employees. The employer also has to bear the cost of monetary compensation, damage to equipment or facilities, losses in the form of production interruptions etc. Besides, the replacement and training of the new employee if an employee is due or disabled is another type of expense incurred by the employer. All such costs can be minimized by enhancing occupational health and safety conditions (Thomason and Pozzebon 2002). OHS management is a part of the organizational management performed by the top management through security measures with aim of preventing accidents at work and injuries. This improves workplace conditions and reduces floor injuries and accidents (Vinodkumar and Bhasi 2011). OHSMs provide safer working environment that lead to increased productivity, reduced costs, improved profitability and performance. (Bottani, Monica et al. 2009), have shown the consequences of not using safety management systems on entity's performance.

\section{Literature Review}

\subsection{Definition of Occupational Health and Safety}

According to the International Labor Organization (ILO) and the World Health Organization (WHO) Committee, occupational health and safety was defined in 1950 as promoting and maintaining a high level of physical and mental social well-being of workers in all occupations. Health and safety at work is the process of ensuring that people in the workplace remain safe and sound in order to increase the ability of workers to perform their tasks and duties. The workplace has become an integral part of the viability of companies for labour unions, employers, society and government. The quality of the work environment affects the motivation and performance of the employees. The health and safety standards set by the organizations aim to promote and maintain the highest physical, mental and social well-being of workers in all sectors by having a positive impact on the health and safety of workers.

\subsection{Safety Climate}

The safety climate indicates the mind-set of employees with regards to the relative essence of safe behaviour. According to (Naveh, Katz-Navon et al. 2006), perceptions of the safety climate are based on four different factors, namely: the perceived relative importance of the safety committee, the importance of safety training, the speed of work, and the perceived status of the safety officer. In a similar context, (Nieva and Sorra 2003) stated that organizational policies, including the improvement in the status of security officer and the strengthening of interpersonal communication, can promote a culture of positive security. Occupational health at work also involves the improvement of the physical, mental and social well-being of workers and the support for the development and maintenance of their employability as well as occupational and social development in the workplace, enabling workers to lead economically productive social lives and contribute positively to sustainable development.

\subsection{Occupational Health and Safety Management}

The management of health and safety at work is based on the risk concept. According to (Kirchsteiger 2005), risk is the possibility that technological activities or natural events have consequences that affect human value. Kirchsteiger (2005), states that a clear assessment of risk identification and subsequent risk minimization measures are essential for the effective management of occupational safety and health risks.

\subsection{A Safety Management System (SMS)}

A safety management system (SMS) can be simply defined as a planned documented and verifiable method for 
managing hazards and associated risks (Harms-Ringdahl 2004). The International Civil Aviation Organization (ICAO) defines safety management system as a systematic approach to safety management, including the necessary organizational structures, responsibilities, policies and procedures (Grote 2012). Safety management system is based on a random collection of best practice activities to promote safety in a variety of industrial contexts. Safety management system requires each organization to follow a systematic approach to safety management, employee welfare and welfare of the general public, and to ensure that organizations and the public are aware of government regulations regarding technical safety, worker protection and safety of employees and respect the health and safety of employees and comply with key and relevant laws and regulations.

According to the World Health Organization (WHO), about one-third of Africa's disease burden is due to environmental hazards (Donkor 2012). According to the World Bank's 2017 report (World Bank, 2017), urbanization and progressive industrialization are progressing in Ghana, and the need to promote occupational health and safety at the workplace must be of great importance and interest to the government and all industries.

\subsection{Organization's Health and Safety}

The health and safety of the organization is an area that deals with the protection and safety of workers in terms of health, safety and well-being. Programs to promote health and safety at work, training, seminars, workshops and legislations have been launched to promote a safe working environment and safe working conditions. Ghanaian employers are required by the Ghana Labor Act 2003 (651) to ensure that their employees are not exposed to conditions that lead to work-related injuries or illness (Amponsah-Tawiah and Mensah 2016). Employees must also perform their duties such that they operate in accordance with the employer's standard operating procedures which take into account health and safety requirements.

The Ghana Labour Act 2003, (651) vision is to ensure that no one should be injured, die, and made ill at work or during working period or at post or on duty. The Ghana Labour Act 2003, (651) is much concerned about ensuring that this vision comes to a reality and to aid and foster a higher productivity. It is believed that health and safety benefits a lot and yields productivity and has made provisions for occupational health and safety. Occupational health and safety has been based mainly on standards, principles, regulations and laws, as well as frequent workplace and work environment inspections to ensure compliance with health and safety standards (Lobel 2005).

\subsection{A healthy Workforce}

A healthy workforce is of great importance to the sustainability of social and economic development at the global, national and district or local level (Griessler and Littig 2005). Health and safe workplaces are the basis or the fundamentals to achieving higher productivity and performance and enhancing the quality working lives for workers in Ghana. The state and the organizations are much concerned about employee's health and safety in order to foster and ensure continuous productivity and economic growth and development.

Employee's health and safety play an important role at the workplace which helps organizations and industries and the national economies of a country. The Ghana Labour Act 2003, (651) section 119 to section 120 touches on health and safety and it is designed to improve safety conditions. Workmen's compensation law 1987 (PNDCL187) is also designed to compensate workers for on-the-job injuries.

\subsection{Occupational Accidents}

Accidents at work usually occur accidentally or unexpectedly and are often caused by people or employees. (Barbic, Casazza et al. 2014), Eurostat defines an accident during work as a sudden event during ongoing work that causes physical or mental harm. (Katsuro, Gadzirayi et al. 2010), indicates that accidents cause pain and suffering to the worker and his family. An accident causes injuries that cause health problems and occur 24 to 48 hours after the damage otherwise it is called disease (McLennan, 2010).

Injuries at work may be as a result of short-term mechanical, direct, chemical or physical effects or by sharp changes in body position, unexpected stress on the body and other physiological changes in the body of the organism (McArdle \& Katch et al., 2010). (Chibuzor \& Jovita, 2018), explain that accidents do not have a single cause and are caused by many factors that occur concursrently. The organization's management is obliged and required to ensure safety and health for every employee while they work. The problem occurs because the organization's management use wrong methods, procedures, and approaches and make bad decisions concerning the OHSMs.

A concern has been voiced by the WHO, which estimates that stress, fatigue and depression may be the main causes of human error in the workplace by 2020 . Health promotion at the workplace complements health and safety measures as part of a joint effort by employers, employees and national authorities to improve the health 
and well-being of employees. The attention given to health and well-being in the work programs are targeted at safeguarding the health among all employees and their families in a form of prevention and assistance programs on issues such as work stress, violence at work, drug and alcohol abuse and the push for tobacco-free work environments (Organization 2016).

\subsection{Promotion of Health And Safety}

The promotion of health and safety involves a careful planning of educational, political, environmental and organizational mechanisms that collectively enhance the living conditions of individuals, groups and communities. To this end, a systematic or systemic approach is needed for the implementation of health promotion programs in the workplace so as to improve the business and working environment, as well as to promote healthy lifestyles and personal development of workers (Cancelliere, Cassidy et al. 2011). In a very good, safe and healthy work environment, injuries and illnesses are reduced thereby increasing productivity (Starc 2018).

Management and employers or co-workers should be able to recognize danger and the endangered persons and make an effective and efficient assessment and classification of risks. Management must put a preventive measure to avoid accidents and manage risks. Management must also take precautionary measures to plan ways and means to avoid, eliminate and prevent risks and accidents. They must also ensure that monitoring devices are put in place to observe, update and assess risk. OHS management is effective in reducing or eliminating occupational accidents and diseases in small to medium term (Tremblay and Badri 2018).

Katsuro, Gadzirayi et al. (2010) regard health and safety at the workplace as a science relating to healthy working environments. According to (Katsuro, Gadzirayi et al. 2010), the reduction of absenteeism is the most important positive influence of health and safety at the workplace on productivity. It shows once again that health and risks, as well as the inability of employees to participate in health promotion and physical activity programs, are associated with a higher rate of employee absenteeism. According to (Chibuzor and Jovita 2018), there is a clear sequence in the sense that healthy and happy workers are more productive, leading to higher investment in health and safety and reduction in accidents, which in turn leads to more productivity gains.

Chibuzor and Jovita (2018) explain in more detail how this is done by investing in high performance OHS practices. According to (Grant, Christianson et al. 2007), the physical well-being of the worker and his / her mind and body must be in good health to focus on a work assigned to him or her. This is a crucial requirement for productivity since high productivity gives the employee a sense of achievement and provides the organization a marginal increase in profits. Health is concerned with the protection of the body and mind from work-related illness (Keyes 2007). According to Keyes (2007), safety is the protection of persons from physical injury. Health and Safety, according to Keyes (2007), is the well-being of people at work or the protection of facilities for the health and well-being of people in the workplace. Safety risks, according to (Evans and Kantrowitz 2002), are the possibility of causing a violent injury to a worker, while the health hazards slowly and cumulatively lead to a deterioration of the worker's health.

\subsection{Safety Policies and Procedures}

This addresses specific issues or threats and presents administrative measures to control occupational hazards and should be used in conjunction with other risk control measures to eliminate or reduce the risk of illness or injury in the workplace. According to (Fernández-Muñiz, Montes-Peón et al. 2009), safety policy is a commitment of safety-conscious organizations that formulate formal objectives such as the principles and guidelines to be followed in relation to health and safety at work. (Goode 2016) also argues that employees should be encouraged to report their safe behavior and unreasonable circumstances in safety policies and procedures and potential workplace hazards to their supervisors. Safety policy is a fundamental part of a company's safety practice as it demonstrates a company's fundamental beliefs and commitment to workstation protection. Fernández-Muñiz and Montes-Peón et al. (2009) stated that safety policy implies the organization's commitment to continuous improvement and it has positive impact on organizational productivity.

Employees are not only obliged to the organization. On the contrary, they expect management to first think about their health and safety needs by implementing appropriate and robust policies. It was found that there is a positive and significant relationship between OHS management and employee affectionate behaviours, normative and a very high commitment to their work. He further explained that, workers who feel exposed to greater risk may resign from their respective jobs which feed into reduction in the labour workforce. In (ABUNAW 2015), a study on OHS management in selected organizations in southwestern Cameroon found that the benefits of OHS management include reducing accidents, improving job longevity and productivity, reducing physical tension and reducing medical compensation costs. 
Corporate staff and their potential are a significant precondition for business success and health and safety management represents a prerequisite for the exploitation for such potentials (Hyršlová, Tomšík et al. 2017). (Group 2012) and (Thiede and Thiede 2015), have found in their review of studies that calculated the financial returns of disease management programs, that the avoidance of medical costs also cause short-term positive results for employers. Safe behavior, including compliance with safety rules and involvement in detecting and eliminating hazards (Naveh, Katz-Navon et al. 2006). Fernández-Muniz et al. (2009) has stated that practices, policies and measures can prevent accidents that benefit both workers and the company. (Gopang, Nebhwani et al. 2017), argued that the performance of organizations can be potentially impacted by the availability of a written safety policy plan. Furthermore, (Amraoui, Pereira et al. 2015) has shown that employees as well as their families and the company are demoralized by fire risks. The incidence of a fire can cause damages to precious assets that eventually in turn affect the reputation of the industry.

The effective implementation of occupational safety and health at work can lead to improved working conditions. OHS management is part of the organizational management performed by the management through safety measures in order to prevent accidents at work and injuries. This improves workplace conditions and reduces floor accidents and injuries (Vinodkumar and Bhasi 2011). OHSMs provide safer jobs that result in increased productivity, reduced costs, enhanced performance and profitability. Ajala (2012) has indicated that adequate workplace lighting influences workers' attitudes, satisfaction, performance and productivity. Inadequate ventilation lowers air quality and can cause infectious diseases that lead to sick leave in the short term. (Seppänen and Fisk 2006) have argued that adequate ventilation causes less pollutants inside and improves performance, while lower ventilation has adverse health effects that lead to unemployment.

Employers must conduct an occupational hazard analysis to determine if there are any hazards that require the use of personal protective equipment (PPE). Employers must provide adequate personal protective equipment (PPE) to workers or employees. Personal Protective Equipment (PPE) is used to minimize exposure to various hazards at the workplace. PSA can include the protection of eyes, face, head and limbs. Face guards, gloves, helmets and respiratory protection are examples of PPE that are commonly used in some organizations. Employees must be trained to ensure that they are aware of the current dangers and the need for PPE and its limitations. They also need to learn to properly take off, adjust and use the PSA. In addition, employees must understand the proper use, care, maintenance and disposal of PPE. Protective clothing is essential for protecting employees from dangerous substances, hazardous environments, and physical injury that ultimately impact their performance. According to (Chandrasekar 2011) personal protective clothing motivates workers to perform tasks in dangerous environments, leading to improvement in performance. Moreover, violating of the use of personal protective equipment is an unsafe practice that may leads to injuries.

\subsection{Productivity}

Productivity is what people can produce in a given time with the least amount of effort and resources. It is also a measure of how well an organization uses resources in goods and services. The work environment can be considered as circumstances, influences, stress, competition, cultural, demographic, economic, and technological factors that influence the survival, business, and growth of an organization. (Awan and Tahir 2015) have stated that a good work environment leads to an increase in employee productivity. In addition, clean floors reduce the risk of slipping and falling, which can result in worker injury.(Gopang, Nebhwani et al. 2017) also stated that slipping and falling can cause injury and mitigating these can reduce the risk of injury and increase worker performance.

According to Macintosh (2005), employees spend most of their lives in the workplace, which greatly influences their mental health, their actions, their abilities, and their performance. It is believed that the best results and highest productivity are the result of a better working environment. Alternatively, several publications dealing with the study of the work environment have shown that factors such as dissatisfaction, disorderly workplaces, and the physical environment play an important role in employee productivity loss. The goal of health and safety program implementation organizations is to promote a safe and secure work environment for employees and general stakeholders to ensure employee efficiency and the bottom line is to maximize productivity, and improve performance. Productivity makes a significant contribution to the company's success by directly translating health and safety into cost savings and profitability.

Organizations must bear direct costs for the health of workers in terms of the cost of medical care and indirect costs in the form of absenteeism and employee disability. These two factors ultimately affect the productivity of the organization. An unsatisfactory work environment can be detrimental to the employee's motivation, which tends to work only minimally to reduce workload. Workers are exposed to risks resulting from the use of 
complex machinery and equipment, noise, factory waste, unprotected machinery, inadequate fire safety measures, and often work under pressure to achieve higher productivity performance.

Health and safety standard is of great importance in the production or manufacturing sectors, as many employees have lost their lives while others have suffered accidents to varying degrees. While knowledge and experience are important components for safe working and accident prevention, employee empowerment and work orientation is essential for a healthier work environment.

\subsection{OHS Performance}

Some researchers describe the concept as performance of a health and safety management system (Cagno, Micheli et al. 2014). Others have defined it as the ability of companies to avoid accidents at work (de Koster, Stam et al. 2011). Some researchers define good occupational safety and health as a record without injuries (accidents at work and occupational diseases or accidents at work) over a long period of time (Tremblay and Badri 2018). A company performs well when OHS management is effective (De Koster et al., 2011). Occupational safety and health is effective in reducing and eliminating occupational accidents and diseases in the short and medium term (Robson, Clarke et al. 2007).

\section{Methodology}

\subsection{Data Collection Instrument}

This paper adopts the survey methodology to collect data from employees of various Banks through the use of questionnaires to gauge the impact of occupational health and safety measures (OHSMs) on the performance of the banks. A five point Likert scale (Likert 1932), was applied in the construction of measurement items, where $1=$ strongly disagree, $2=$ disagree, $3=$ neutral, $4=$ agree and $5=$ strongly agree. The population of the inquiry was banking institutions in Ghana that are directly involved and adhere to OHSMs. Stratified sampling technique and purposive sampling were, however, employed in choosing the respondents for the investigation. A total of 250 participants were considered for this survey. We computed the dependability of the data collected by utilizing Cronbach's alpha.

With the aid of SPSS version 16.0 (Inc 1994), simple regression and Pearson correlation were used to test the hypotheses in order to have a clear grasp of the statistical relationships between or among the variables. The rationale behind the use of Pearson correlation analysis is to quantify the connection between dependent and independent variables (Mukaka 2012). For example, Pearson correlation analysis determines whether there exists any relationship between variables and the direction of that relationship (positive or negative), if any. Furthermore, it tells the magnitude of the relationship between variables. As for regression analysis, it is employed to point out the level of variations in dependent variables due to independent variables (Merlo, Chaix et al. 2006).

\section{Results and Discussion}

The reliability of data was computed using Cronbach's alpha coefficient which gives a good and consistent yield of 0.8 .

\subsection{Demographics of Respondents}

Total survey questionnaires were sent to private and public banks in the Greater-Accra region of Ghana and completed questionnaires were used for the analysis. $30 \%$ of the respondents came from public banks while $70 \%$ came from private banks.

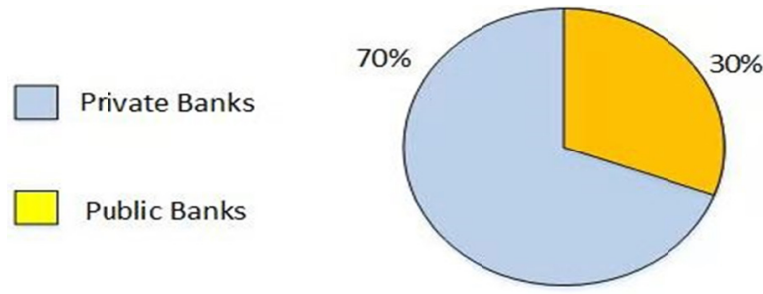

Figure 1. Response from the Banks

\subsection{Operation Periods of the Banks}

Based on data collected, all of the respondents came from Banks who were in existence: for more than 5 years. 
About $20 \%$ of the respondents came from private banks that were in existence for more than 10 years. About $5 \%$ of the respondents came from public banks that were in existence for more than 30 years.

\subsection{Working Experience of Respondents}

Out of the statistical analysis, it was found that $20 \%$ of the respondents had 5-10 years working experience in the private sector. $30 \%$ of the respondents had $15-35$ years working experience in the public sector.

\subsection{Age of Respondents}

Statistical analyses found that $20 \%$ of respondents were between 25 and 30 years old, $30 \%$ between 31 and 35 years, $10 \%$ between 36 and 40 years, $15 \%$ between 41 and 45 years, $11 \%$ between 46 and 50 years and $14 \%$ between 51 and 55 years.

\subsection{Performance Indicators for Banks}

Respondents working in different banks were queried to indicate their degree of agreement with the questions in the questionnaires. They were implored to rate the variables on a 5-point Likert scale. We calculate the mean $(\overline{\mathrm{X}})$ and the standard deviation (SD) according to the analysis of the collected data. The results are as follows:

Table 1 shows the results of data analysis for various bank performance indicators. As can be seen from the table, the mean $(\overline{\mathrm{X}})$ for all variables were near to 4 indicating that respondents concurred that as a result of safety practices and programs, higher productivity has been achieved, sales has been increased, the bank has achieved its target for the fiscal year and there has been fast, reliable and convenient delivery services. In addition, participants affirm that the banks have different products and services, enough resources, funds and a sound financial system, less service cost, goodwill and good reputation. This means the banks have improved upon their services and therefore have more profits and surpluses, effective and efficient operations and services, more loyal customers, smooth supervision and monitoring, higher level of customer satisfaction and promotion offers and programs.

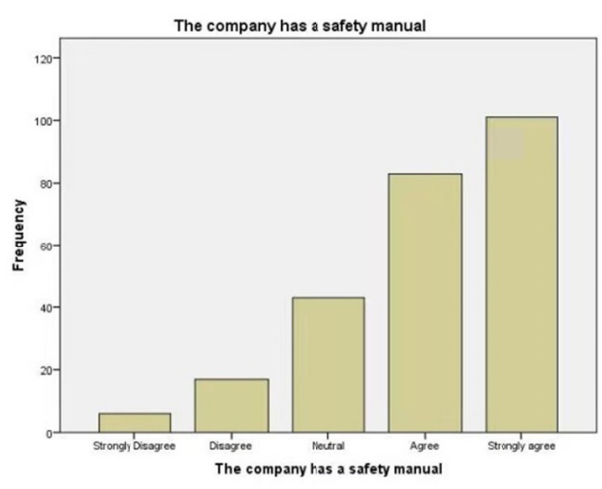

(a)

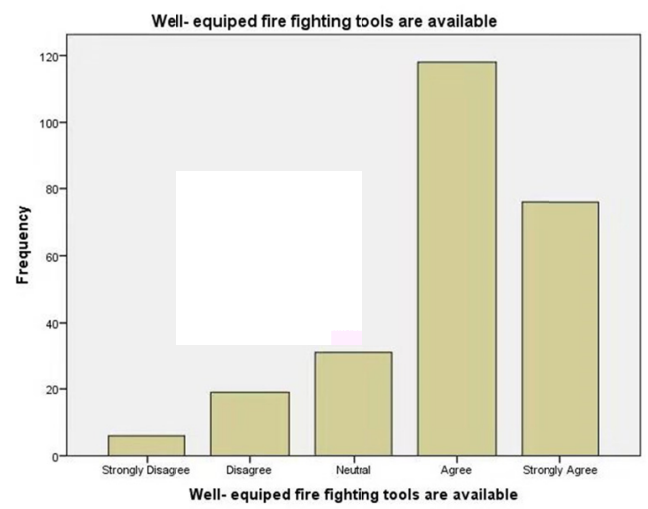

(c)

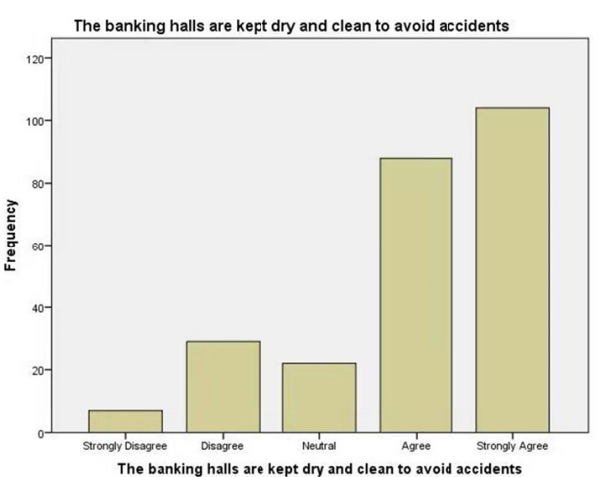

(b)

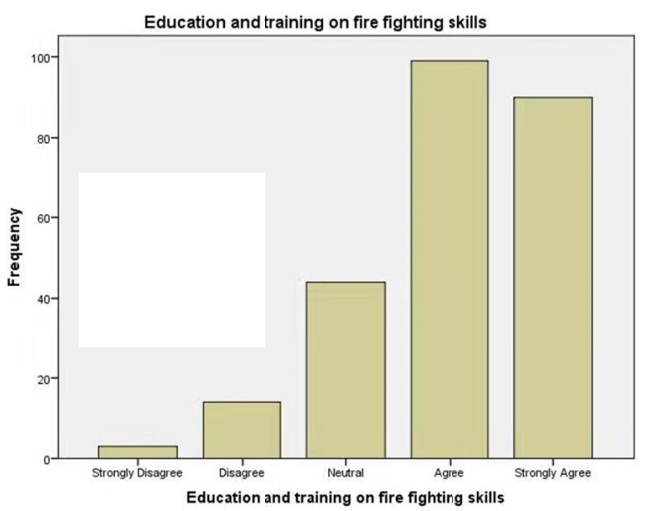

(d)

Figure 2. The frequency of measurement items against questions (a) the company has a safety manual (b) the banking halls are kept dry and clean to avoid accidents (c) well-equipped firefighting tools are available (d) 
education and training on firefighting skills

\subsection{Occupational Health and Safety Measures (OHSMs) in Banks}

Participants from different banks indicated their level of agreement with the OHSMs-based questions in the questionnaires. They were requested to rank the variables on a 5-point Likert scale. Based on the data analysis, we computed the mean $(\overline{\mathrm{X}})$ and standard deviation $(\mathrm{SD})$ and the results are as follows:

Table 2 shows the results of data analysis for various banks OHSM indicators. The results show that the mean $(\overline{\mathrm{X}})$ for all variable were quite close to 4 indicating that participants concurred that the banks have a safety manual, PPE is provided for all workers, the banking halls are kept dry and clean to avoid accidents. Furthermore, the respondents agreed that there is quality indoor air ventilation, sufficient illumination available in the office, education and training on firefighting skills, abundant supply of first aid Kits at the workplace, presence of clean and hygienic lavatories, satisfactory conditions in the washroom, availability of dustbins at vantage points and consistent review of accident preventive measures. The mean values also imply that respondents agree that there are appropriate fire exists during emergency and well-equipped firefighting tools in the office among others.

Table 1. Performance

\begin{tabular}{lll}
\hline Variable & Mean & Std. Deviation \\
\hline Higher productivity has been achieved & 4.2134 & 3.9979 \\
An increment in sales & 4.0753 & 1.03300 \\
The organization has achieved its target for the fiscal year & 3.9707 & 0.89874 \\
Delivery services are fast, reliable and convenient & 4.0146 & 1.09658 \\
The organization has different products and services & 4.0753 \\
The organization has enough resources, funds and a sound financial system & 3.9247 \\
Service cost are less expensive & 3.9958 \\
The organization has a goodwill and a good reputation & 3.9665 \\
The organization has improved upon its services & 4.249 \\
The organization has more profits and surpluses & 4.0418 \\
Effectiveness and efficiency of operations and services & 3.7699 \\
More loyal customers & 4.0753 \\
Smooth supervision and monitoring & 3.9979 \\
Higher level of customer satisfaction & 3.9456 \\
Promotion offers and programs & 0.8974 \\
\hline
\end{tabular}

Table 2. OHSMs

\begin{tabular}{|c|c|c|}
\hline Variable & Mean & Std. Deviation \\
\hline The company has a safety manual & 4.0240 & 1.03329 \\
\hline PPE is provided for all workers & 4.1200 & 2.69493 \\
\hline $\begin{array}{l}\text { The banking halls are kept dry and clean to } \\
\text { avoid accidents }\end{array}$ & 4. 0120 & 1.10669 \\
\hline There is a quality indoor air ventilation & 3.9120 & 1.07559 \\
\hline $\begin{array}{l}\text { Sufficient illumination is available in the } \\
\text { office }\end{array}$ & 4.0240 & 1.02549 \\
\hline $\begin{array}{l}\text { Appropriate fire exists are available during } \\
\text { emergency }\end{array}$ & 4.0360 & 0.95832 \\
\hline $\begin{array}{l}\text { Well-equipped firefighting tools are available } \\
\text { in the office }\end{array}$ & 3.9560 & 0.97461 \\
\hline Education and training on firefighting skills & 4.0360 & 0.93284 \\
\hline $\begin{array}{l}\text { Abundant supply of first aid Kits at the } \\
\text { workplace }\end{array}$ & 4.0800 & 0.90603 \\
\hline Presence of clean and hygienic lavatories & 4.1120 & 0.84754 \\
\hline $\begin{array}{l}\text { Workers are satisfied with the conditions in } \\
\text { the washroom }\end{array}$ & 4.2240 & 0.84420 \\
\hline Availability of dustbins at vantage points & 3.9880 & 0.97141 \\
\hline Consistent review of accident preventive & 3.9680 & 0.84963 \\
\hline
\end{tabular}




\begin{tabular}{|c|c|c|}
\hline \multicolumn{3}{|l|}{ measures } \\
\hline Regular medical check-up for workers & 3.7240 & 0.92696 \\
\hline $\begin{array}{l}\text { Presence of directional markings at the } \\
\text { workplace }\end{array}$ & 3.8400 & 0.83498 \\
\hline $\begin{array}{l}\text { Availability of clean and safe drinking water } \\
\text { for workers }\end{array}$ & 3.7640 & 0.89863 \\
\hline Continuous break schedules for workers & 3.9960 & 0.76834 \\
\hline Periodic risk and health assessment & 4.0160 & 0.79642 \\
\hline $\begin{array}{l}\text { Provision of safe and comfortable desks and } \\
\text { seats at the workplace }\end{array}$ & 4.0120 & 0.78889 \\
\hline $\begin{array}{l}\text { Availability of safety suggestion box at the } \\
\text { workplace }\end{array}$ & 3.9240 & 0.82520 \\
\hline
\end{tabular}

\subsection{The Impact of OHSMs on the Performance of Banks}

Table 3(a). Model summary (regression and correlation of the mean of OHSMs against the total mean of Banks' performance)

\begin{tabular}{|c|c|c|c|c|c|}
\hline \multirow[t]{2}{*}{ Model } & \multicolumn{2}{|c|}{ Unstandardized Coefficients } & \multirow[t]{2}{*}{$\mathrm{t}$} & \multirow[t]{2}{*}{ Sig. } & \multirow{2}{*}{$\begin{array}{l}\text { Pearson } \\
\text { coefficient }\end{array}$} \\
\hline & B & Std. Error & & & \\
\hline (Constant) & 14.258 & 5.264 & 2.709 & .007 & \\
\hline OHSMS & .558 & .069 & 8.067 & .000 & .456 \\
\hline
\end{tabular}

Table 3(b) Regression of variable (regression and correlation of the mean of OHSMs against the total mean of Banks' performance)

\begin{tabular}{llllllll}
\hline Model & R & R Square & Adjusted R Square & Std. Error of the Estimate & F Change & Df Sig. F Change \\
\hline 1 & $.456^{\mathrm{a}}$ & .208 & .205 & 4.76618 & 65.073 & 1 & .000 \\
\hline
\end{tabular}

Table 3(a) shows the results of the regression and the correlation when the OHSMs average decreased compared to the overall average of banks' performance. The value of $r(0.456)$ for the OHSM implies that there was a clear but slightly modest positive interrelation between the OHSMs and the Banks' performance, which is remarkable with a p-value of 0.000 and is $<0.007$. This means that the OHSMs lend slightly positively to the performance of the banks. Table 3 (b) indicates that the regression value where R-squared is 0.208 . This shows that the deviation of the banks' performance of $20.8 \%$ is due to these safety practices. Moreover, this shows that there are other direct factors such as the training of workers, the regular medical examination of workers and the provision of PPE to all workers, which also affects the performance of the banks.

\section{Conclusion}

In this study, we examined the relationship between occupational health and safety and the performance of banks in Ghana. The result of the Pearson correlation $(r=0.456$, $p$-value $<0.007)$ shows that there was a modest but positive correlation between the OHSMs and the banks' performance, which is remarkable. In addition, the result of the regression analysis $(\mathrm{R}$-squared $=0.208$ ) shows that the performance of the banks fluctuates by $20.8 \%$ due to OHSMs. Based on our findings, we recommend that Banks in Ghana should improve health and safety practices in terms of ensuring regular medical check-ups for workers, providing clean and safe drinking water for workers and placing directional markings at the workplace. In addition, there is the need for the Banks to be well equipped with firefighting tools in their offices and to ensure adequate indoor air ventilation. Government, through the Bank of Ghana and Ghana National Fire Service, should set-up a policy framework for the implementation of OHSMs and ensure that the Banks comply with them. This will help to improve upon the effectiveness and efficiency of Banks in Ghana to enhance economic growth and social development.

\section{References}

Abunaw, A. N. (2015). Management of Occupational Health and Safety in Selected Organisations of the South West Region of Cameroon.

Ajala, E. M. (2012). The influence of workplace environment on workers' welfare, performance and productivity. The African Symposium. 
Amponsah-Tawiah, K., \& Mensah, J. (2016). Occupational health and safety and organizational commitment: evidence from the Ghanaian mining industry. Safety and Health at work, 7(3), 225-230. https://doi.org/10.1016/j.shaw.2016.01.002

Amraoui, M., Pereira, M. G., DaCamara, C. C., \& Calado, T. J. (2015). Atmospheric conditions associated with extreme fire activity in the Western Mediterranean region. Science of the Total Environment, 524, 32-39. https://doi.org/10.1016/j.scitotenv.2015.04.032

Awan, A. G., \& Tahir, M. T. (2015). Impact of working environment on employee's productivity: A case study of Banks and Insurance Companies in Pakistan. European Journal of Business and Management, 7(1), 329-345.

Barbic, F., Casazza, G., Zamunér, A. R., Costantino, G., Orlandi, M., Dipaola, F., Capitanio, C., Achenza, S., Sheldon, R., \& Furlan, R. (2014). Driving and working with syncope. Autonomic Neuroscience, 184, 46-52. https://doi.org/10.1016/j.autneu.2014.05.006

Bottani, E., Monica, L., \& Vignali, G. (2009). Safety management systems: Performance differences between adopters and non-adopters. Safety Science, 47(2), 155-162. https://doi.org/10.1016/j.ssci.2008.05.001

Cagno, E., Micheli, G., Jacinto, C., \& Masi, D. (2014). An interpretive model of occupational safety performance for Small-and Medium-sized Enterprises. International Journal of Industrial Ergonomics, 44(1), 60-74. https://doi.org/10.1016/j.ergon.2013.08.005

Cancelliere, C., Cassidy, J. D., Ammendolia, C., \& Côté, P. (2011). Are workplace health promotion programs effective at improving presenteeism in workers? A systematic review and best evidence synthesis of the literature. BMC public health, 11(1), 395. https://doi.org/10.1186/1471-2458-11-395

Chandrasekar, K. (2011). Workplace environment and its impact on organisational performance in public sector organisations. International Journal of Enterprise Computing and Business Systems, 1(1), 1-19.

Chibuzor, A. A., \& Jovita, O. U. (2018). Safety and Health Management and Organizational Productivity. Global Journal of Management And Business Research.

De Koster, R. B., Stam, D., \& Balk, B. M. (2011). Accidents happen: The influence of safety-specific transformational leadership, safety consciousness, and hazard reducing systems on warehouse accidents. Journal of Operations management, 29(7-8), 753-765. https://doi.org/10.1016/j.jom.2011.06.005

Donkor, D. (2012). Evaluation of health and safety practices and policies at Electricity Company of Ghana, the Case of the Ashanti East Region.

Evans, G. W., \& Kantrowitz, E. (2002). Socioeconomic status and health: the potential role of environmental risk exposure. Annual Review of Public Health, 23(1), 303-331. https://doi.org/10.1146/annurev.publhealth.23.112001.112349

Fernández-Muñiz, B., Montes-Peón, J. M., \& Vázquez-Ordás, C. J. (2009). Relation between occupational safety management and firm performance. Safety science, 47(7), 980-991. https://doi.org/10.1016/j.ssci.2008.10.022

Goode, E. (2016). Deviant behavior, Routledge. https://doi.org/10.4324/9781315643632

Gopang, M. A., Nebhwani, M., Khatri, A., \& Marri, H. B. (2017). An assessment of occupational health and safety measures and performance of SMEs: An empirical investigation. Safety science, 93, 127-133. https://doi.org/10.1016/j.ssci.2016.11.024

Grant, A. M., Christianson, M. K., \& Price, R. H. (2007). Happiness, health, or relationships? Managerial practices and employee well-being tradeoffs. Academy of Management Perspectives, 21(3), 51-63. https://doi.org/10.5465/amp.2007.26421238

Griessler, E., \& Littig, B. (2005). Social sustainability: a catchword between political pragmatism and social theory. International Journal for Sustainable Development, 8(1/2), 65-79. https://doi.org/10.1504/IJSD.2005.007375

Grote, G. (2012). Safety management in different high-risk domains-all the same? Safety Science, 50(10), 1983-1992. https://doi.org/10.1016/j.ssci.2011.07.017

Group, J. J. W. (2012). Guidelines for the clinical use of 24 hour ambulatory blood pressure monitoring (ABPM)(JCS 2010). Circulation Journal, 76(2), 508-519. https://doi.org/10.1253/circj.CJ-88-0020 
Harms-Ringdahl, L. (2004). Relationships between accident investigations, risk analysis, and safety management. Journal of Hazardous materials, 111(1-3), 13-19. https://doi.org/10.1016/j.jhazmat.2004.02.003

Hyršlová, J., Tomšík, P., \& Vnoučková, L. (2017). Relation Between Sustainability-Related Communication and Competitiveness in the Chemical Industry. Acta Universitatis Agriculturae et Silviculturae Mendelianae Brunensis, 65(1), 283-292. https://doi.org/10.11118/actaun201765010283

Inc, S. (1994). SPSS 6.1 for Windows student version. Prentice Hall.

Katsuro, P., Gadzirayi, C., Taruwona, M., \& Mupararano, S. (2010). Impact of occupational health and safety on worker productivity: A case of Zimbabwe food industry. African Journal of Business Management, 4(13), 2644-2651.

Keyes, C. L. (2007). Promoting and protecting mental health as flourishing: A complementary strategy for improving national mental health. American psychologist, $62(2), \quad 95$. https://doi.org/10.1037/0003-066X.62.2.95

Kirchsteiger, C. (2005). Review of industrial safety management by international agreements and institutions. Journal of risk research, 8(1), 31-51. https://doi.org/10.1080/0003684022000026610

Likert, R. (1932). A technique for the measurement of attitudes. Archives of psychology.

Lobel, O. (2005). Interlocking regulatory and industrial relations: The governance of workplace safety. Admin. $L$. Rev. 57, 1071.

Macintosh, J. (2005). Experiences of Workplace Bullying in a Rural Area. Issues in Mental Health Nursing, 26(9), 893. https://doi.org/10.1080/01612840500248189

McArdle, W. D., Katch, F. I., \& Katch, V. L. (2010). Exercise physiology: nutrition, energy, and human performance, Lippincott Williams \& Wilkins.

McLennan, S. N. (2010). Measurement, causes, and impacts of vascular cognitive impairment and vascular depression.

Merlo, J., Chaix, B., Ohlsson, H., Beckman, A., Johnell, K., Hjerpe, P., Råstam, L., \& Larsen, K. (2006). A brief conceptual tutorial of multilevel analysis in social epidemiology: using measures of clustering in multilevel logistic regression to investigate contextual phenomena. Journal of Epidemiology \& Community Health, 60(4), 290-297. https://doi.org/10.1136/jech.2004.029454

Mukaka, M. M. (2012). A guide to appropriate use of correlation coefficient in medical research. Malawi Medical Journal, 24(3), 69-71.

Naveh, E., Katz-Navon, T., \& Stern, Z. (2006). Readiness to report medical treatment errors: the effects of safety procedures, safety information, and priority of safety. Medical Care, 117-123. https://doi.org/10.1097/01.mlr.0000197035.12311.88

Nieva, V., \& Sorra, J. (2003). Safety culture assessment: a tool for improving patient safety in healthcare organizations. BMJ Quality \& Safety, 12(suppl 2), ii17-ii23. https://doi.org/10.1136/qhc.12.suppl_2.ii17

Organization, W. H. (2016). Second Regional Forum of WHO Collaborating Centres in the Western Pacific, Manila, Philippines, 28-29 November 2016: meeting report, Manila: WHO Regional Office for the Western Pacific.

Robson, L. S., Clarke, J. A., Cullen, K., Bielecky, A., Severin, C., Bigelow, P. L., Irvin, E., Culyer, A., \& Mahood, Q. (2007). The effectiveness of occupational health and safety management system interventions: a systematic review. Safety science, 45(3), 329-353. https://doi.org/10.1016/j.ssci.2006.07.003

Seppänen, O. A., \& Fisk, W. (2006). Some quantitative relations between indoor environmental quality and work performance or health. Hvac\&R Research, 12(4), 957-973. https://doi.org/10.1080/10789669.2006.10391446

Starc, J. (2018). Stress Factors among Nurses at the Primary and Secondary Level of Public Sector Health Care: The Case of Slovenia. Open access Macedonian Journal of Medical Sciences, 6(2), 416. https://doi.org/10.3889/oamjms.2018.100

Thiede, I., \& Thiede, M. (2015). Quantifying the costs and benefits of occupational health and safety interventions at a Bangladesh shipbuilding company. International journal of occupational and environmental health, 21(2), 127-136. https://doi.org/10.1179/2049396714Y.0000000100 
Thomason, T., \& Pozzebon, S. (2002). Determinants of firm workplace health and safety and claims management practices. ILR Review, 55(2), 286-307. https://doi.org/10.1177/001979390205500205

Tremblay, A., \& Badri, A. (2018). Assessment of occupational health and safety performance evaluation tools: State of the art and challenges for small and medium-sized enterprises. Safety science, 101, $260-267$. https://doi.org/10.1016/j.ssci.2017.09.016

Vinodkumar, M., \& Bhasi, M. (2011). A study on the impact of management system certification on safety management. Safety Science, 49(3), 498-507. https://doi.org/10.1016/j.ssci.2010.11.009

\section{Appendix A. Questionnaires}

Jiangsu University, Zhenjiang, P.R. China

\section{Occupational Health and Safety Measures (OHSMs) in Ghana Survey}

\section{Section A: Background Information}

What is the nature of your job?

Do you work in a public or private bank?

How long has your organisation been in existence?

How many years of work experience do you have?

What is your age?

\section{Section B: Occupational Health and Safety Measures (OHSMs)}

Score the following statements by ticking the appropriate box which indicates the extent to which they apply to your organization.

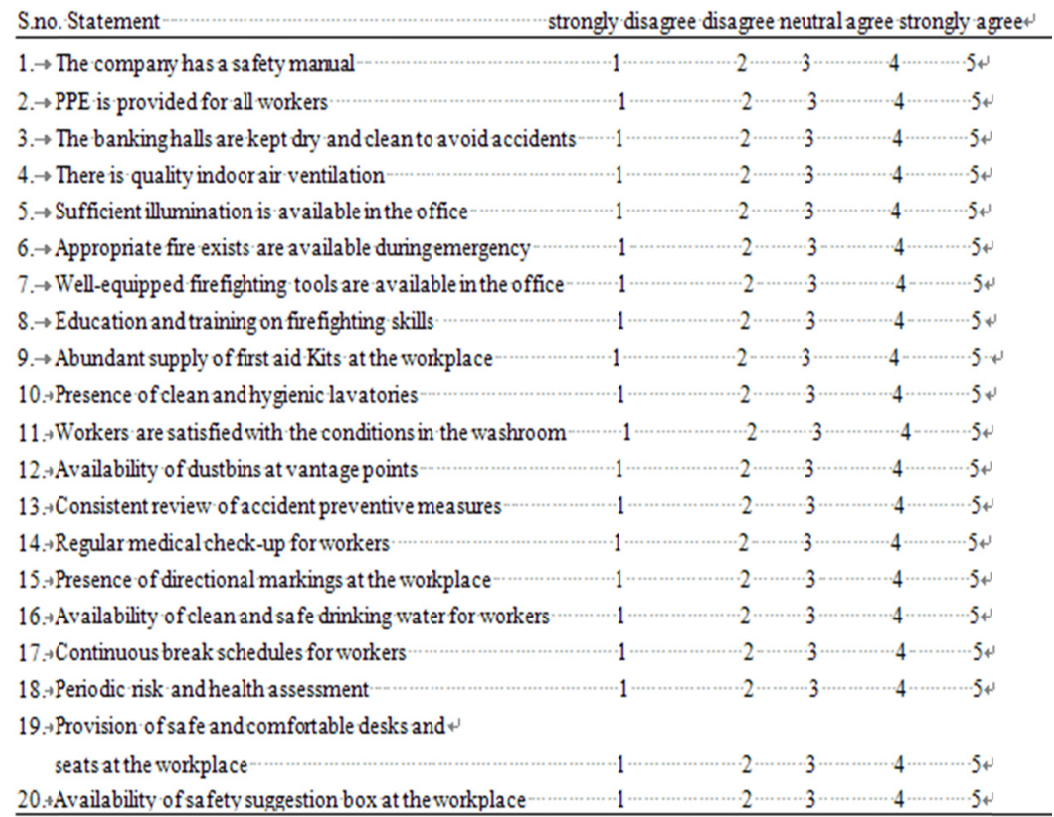




\section{Section C: Banks Performance}

Score the following statements by ticking the appropriate box which indicates the extent to which they apply to your organization.

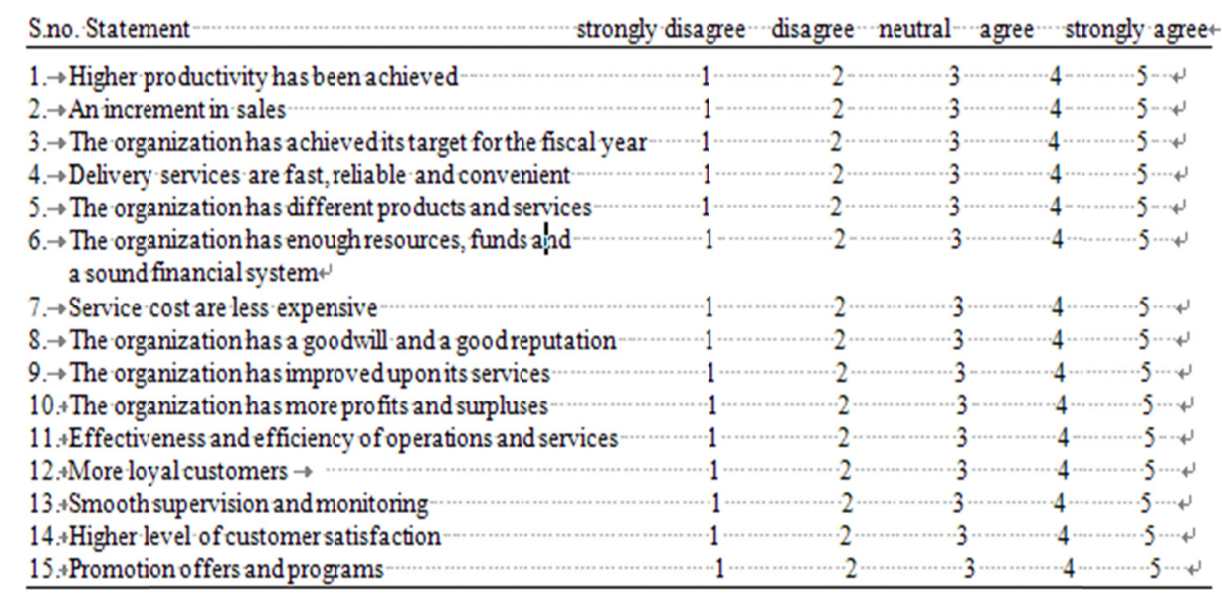

\section{Copyrights}

Copyright for this article is retained by the author(s), with first publication rights granted to the journal.

This is an open-access article distributed under the terms and conditions of the Creative Commons Attribution license (http://creativecommons.org/licenses/by/4.0/). 